\title{
USE OF STRUCTURED DECISION SUPPORT FOR VALUING LOST CULTURAL BENEFITS ASSOCIATED WITH ENVIRONMENTAL INJURIES
}

\author{
WILLIAM TROUSDALE ${ }^{1} \&$ DAVID A. HANSON ${ }^{2}$ \\ ${ }^{1}$ EcoPlan International, Vancouver, BC, Canada \\ ${ }^{2}$ Hanson, Blaine, WA, USA
}

\begin{abstract}
Various environmental regulations require the avoidance from, mitigation of, and/or compensatory restoration of lost ecosystem services associated with environmental injuries. The ability of environmental managers to put various categories of ecosystem services into effective operational terms for environmental regulation and decision making has been highly variable to date. Quantitative valuation of the benefits associated with provisioning services (e.g., timber), as well as the direct human use of natural resources (e.g., recreation and tourism), using traditional market-based and revealed preference economic frameworks has been widely adopted. In contrast, valuation of non-material cultural services (e.g., bequest, existence, spiritual, or aesthetic) has been more challenging with various types of environmental assessments relying (1) on narrative descriptions (which define the benefit of an ecosystem service but struggle to define its value), (2) established but not widely accepted contingent valuation economic frameworks, or (3) ecological-based equivalency analysis based on a single habitat or ecological production metric while assuming other regulating, non-material cultural services, and supporting services are equivalent and substitutable on a per unit basis. The lack of effective methods to communicate and appropriately address the value of non-material cultural benefits associated environmental injuries has been an ongoing source of conflict for environmental managers. This paper presents a method for scaling the value of threatened or lost non-material cultural services associated with environmental injuries based on a structured decision support (SDS) approach, which draws from decision sciences (e.g., multi-criteria attribute) and negotiation theory (e.g., interest based). It has been successfully applied in both Indigenous and non-Indigenous groups in Canada and the US. The value of the benefit of cultural services or goods is estimated by scaling "Benefit-to-Benefit" when possible. In some contexts, the use of "Benefit-to-Cost" method of scaling is warranted. Neither scaling approach requires stakeholders to state a direct monetary value for non-material losses.
\end{abstract}

Keywords: structured decision support, cultural values, cultural ecosystem benefits, environmental injuries.

\section{INTRODUCTION}

Regulatory requirements in countries around the world, underpinned by growing ethical concerns for social justice, are increasingly mandating that responsible parties address cultural losses that result from environmental injuries caused by resource development, exclusion, degradation or destruction. Effective methods to address this difficult issue have been fraught with challenges, such as of translating losses into analytical frameworks that can be incorporated into broader assessments and scaling losses in a way that improves dialogue, leading to more effective and acceptable avoidance, mitigation, restoration and compensation responses. The purpose of this paper is to describe a structured decision support (SDS) approach that has successfully addressed these cultural loss challenges in many contexts.

One of the most important efforts to bring cultural loss issues to the forefront of assessment was chronicled fifteen years ago in the Millennium Ecosystem Assessment [1]. Here, the use of an ecosystem framework for the conservation, preservation, and restoration of natural resource functions and services was popularized. The Millennium Assessment 
broadly defined ecosystem services as the benefits people obtain from ecosystems and were defined as provisioning, regulating, cultural, and supporting services. Cultural ecosystem services were defined as the nonmaterial benefits people obtain from ecosystems through spiritual enrichment, cognitive development, reflection, recreation, and aesthetic experiences (e.g., cultural diversity, spiritual and religious values, knowledge systems, educational values, inspiration, aesthetic values, social relations, sense of place, cultural heritage values, and recreation and ecotourism).

The use of an ecosystem service framework to understand human and environmental interactions has grown rapidly [2], [3]. However, much of this literature has suggested modifications in the classification systems of ecosystem services or clarification as to the type and nature of services provided by different types of ecosystems (e.g., forests, lakes, etc.). For example, Haines-Young and Potschin [4] define a common international classification of ecosystem services (CICES). Other literature has been of a conceptual, qualitative nature with a focus on clarification of the inter-relationships between ecosystem services, ecosystem benefits, and ecosystem values (Fig. 1; [5], [6]) and the development of relevant benefit indicators [7]. Examples of quantitative categories of methods to understand cultural ecosystem services and their subsequent benefits includes linking cultural benefits with ecosystem attributes and geospatial mapping [8]-[11]. Although useful for understanding and theoretical application of an ecosystem services framework for evaluation of anthropogenic impacts, the above categories of qualitative and quantitative methods have not been widely used for scaling of the loss of cultural ecosystem benefits associated with environmental injuries with appropriate levels of avoidance, mitigation, and compensatory restoration activities.

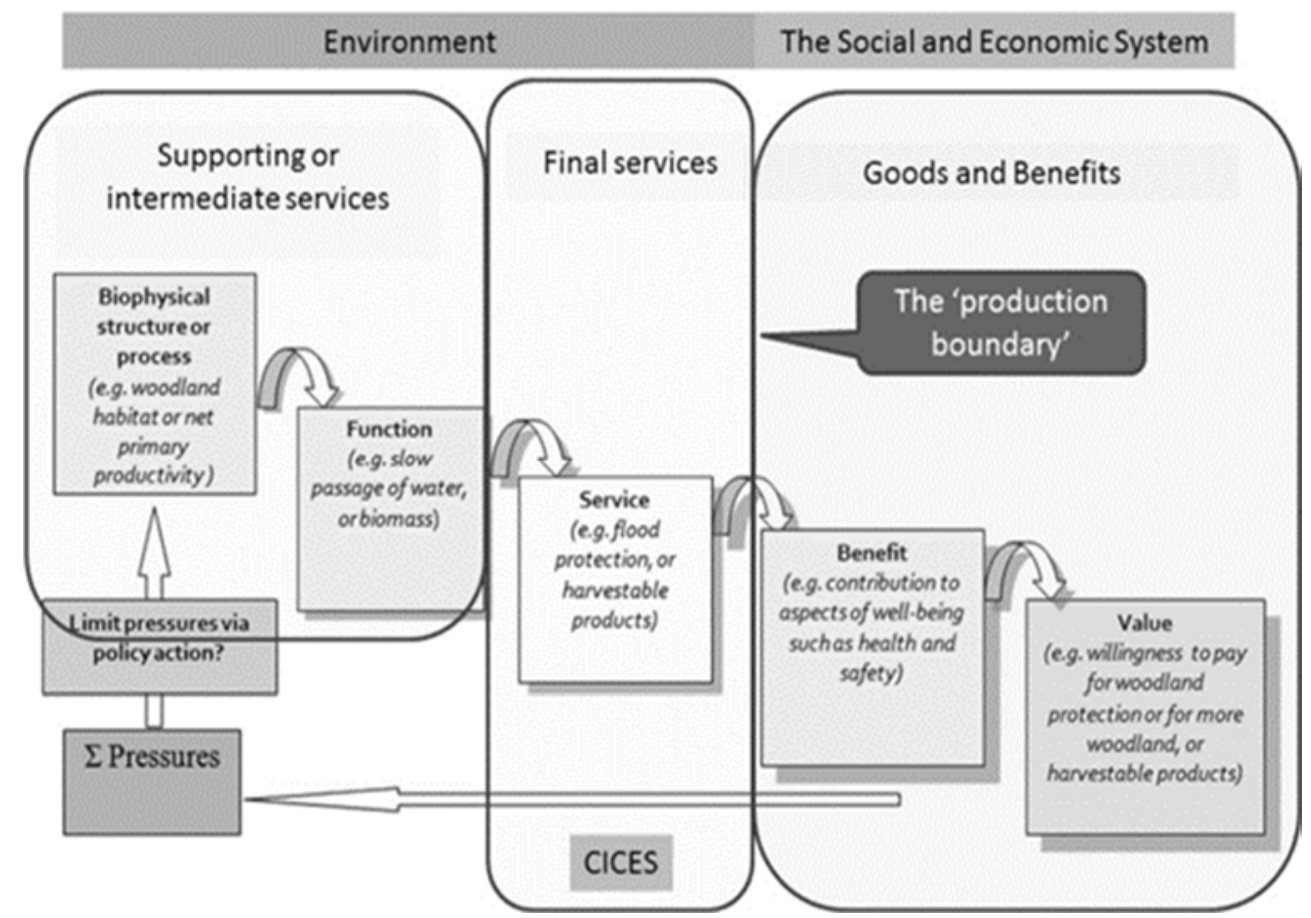

Figure 1: The ecosystem service cascade model. (Source: Potschin-Young et al., 2018.) 
The ability to apply relevant quantified estimates of the benefits and value of ecosystem services is highly variable. The U.S. Environmental Protection Agency's Science Advisory Board [12] provides a comprehensive review of potential methods for evaluating ecosystem services. Three categories of economic-based methods for valuing the benefits of natural resources are as follows: market-based methods, revealed preference methods, and stated preference methods.

Market-based methods have been used for decades to provide quantitative estimates of the value of provisioning ecosystem services and subsequent benefits (e.g., the economic value observed in the market for forest timber, commercial and recreational fisheries, and freshwater supply).

Revealed preference economic methods attempt to establish financial values for services and benefits not traded in markets by relating their value to the costs for the consumption of goods that are traded in markets. Values of cultural ecosystem benefits that have a direct human use have been estimated using methods like hedonic pricing or travel cost pricing (e.g., recreation: fishing, camping, whale watching, ecotourism).

Stated preference models have been used when values of cultural ecosystem benefits cannot be revealed or inferred from measuring people's actual choices; instead, people are asked to state their preferences between selected ecosystem benefits and their hypothetical economic value (i.e., willingness to pay or willingness to accept payment in lieu of the benefits from a good or service). One area where willingness to pay methods are commonly applied is to estimate the value of non-market ecosystem and cultural service benefits and losses. However, use of this method is difficult to apply and has met with much criticism [13], [14]

A fourth commonly used approach to quantify the benefits of an ecosystem service which avoids the direct economic valuation of the benefit of the resource or its service, has been through the use of equivalency-based methods, such as Habitat Equivalency Analysis (HEA) and Resource Equivalency Analysis (REA). HEA, and to a lesser extent, REA, have been used for a wide variety of applications which require scaling past or potential damages with compensatory actions to offset the environmental injuries. HEA utilizes a Service-to-Service approach to equate estimates of lost ecosystem services on a habitat basis with compensable gains in ecosystem services from a portfolio of alternative conservation, preservation, or restoration activities. The ecosystem services metric for HEA can be represented in a wide variety of ways.

It is important to note however, that many potential categories of injured ecosystem services are not directly assessed but instead it is assumed that the level of bundled ecosystem services, and their corresponding benefits and values, between the injury and the potential restoration alternatives are functionally equivalent on a per unit basis (e.g., the cultural benefits and value per acre of a damaged forest is equivalent to the per acre value of the compensatory restoration activities). REA is like HEA in its underlaying theory except the metrics used to assess of environmental injuries and benefits are directly measured in ecological terms (e.g., productivity or numbers of a species) rather than conceptual or constructed.

Although habitat-based equivalency methods may be sufficient in some applications, Olander et al. [7] would classify methods that quantify ecological services but only discuss social or cultural services in a narrative manner as a partial valuation that falls short of being a "best practice" (Fig. 2). The economic value of mitigation or compensatory restoration using HEA and REA is based on the implementation costs for the compensatory activities rather than a direct quantification of the resource and its services and associated benefits in economic terms. 


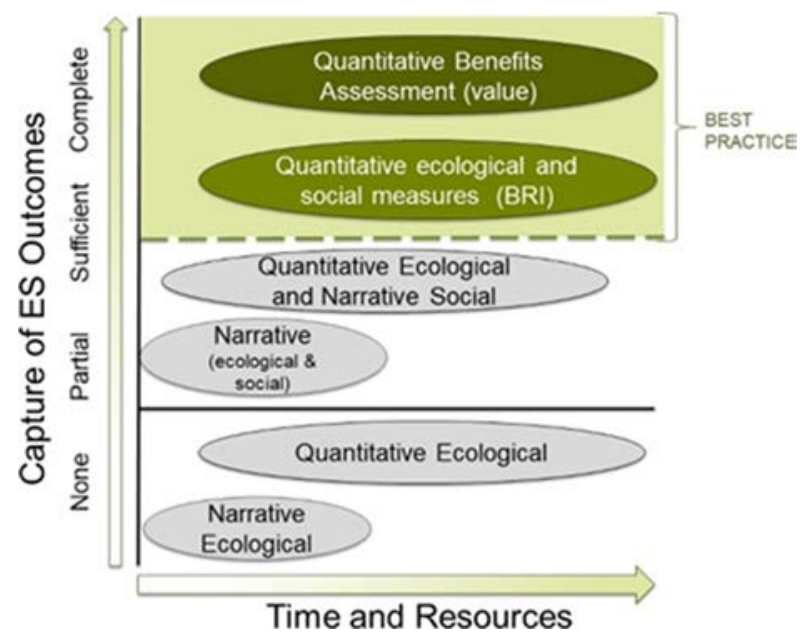

Figure 2: Approaches for capturing ecosystem service outcomes in assessments and decision making. (Source: Olander et al., 2018.)

The application of both conceptual and quantitative methods for evaluating ecosystem services has provided society with a more holistic perspective for the evaluation of the relationships between human activities, environmental health, and environmental benefits. However, many challenges remain, especially regarding the evaluation of cultural ecosystem services. Fish et al. [15] provide an interesting conceptual definition of cultural ecosystem services (i.e., the interactions between cultural practices and environmental spaces; Fig. 3).

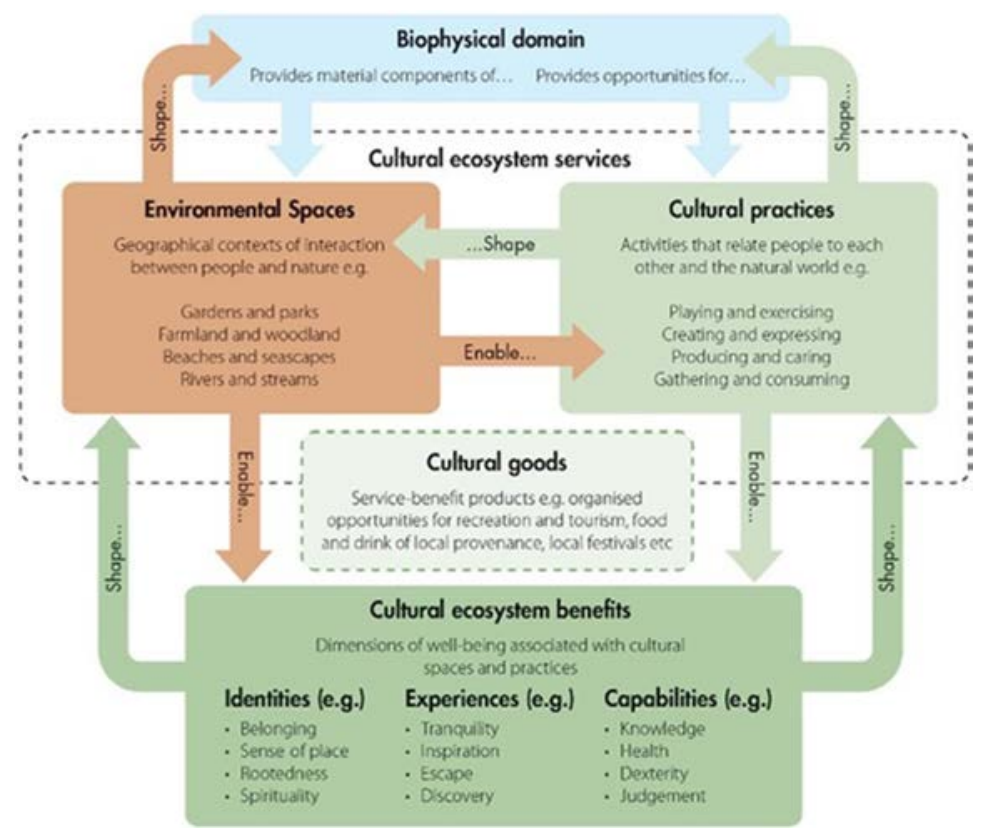

Figure 3: Conceptual framework for cultural ecosystem services. (Source: Fish et al., 2016.) 
They capture well the dynamics of how environmental spaces enable cultural practices which in turn can shape the environmental spaces. Similar to the conceptual model of Potschin-Young et al. [5], cultural ecosystem services enable cultural ecosystem benefits. Their model does not, however, reflect the cascading relationship between cultural benefits and their values. Instead, Fish et al. [15] divide cultural benefits into two categories, those whose values are often measured using traditional market-based or revealed preference natural resource economic methods (i.e., cultural ecosystem goods) and those benefits which can't be valued by these methods but instead are typically addressed using narrative qualitative approaches or quantitative stated preference methods.

Building on this growing body of ecosystem services knowledge, the SDS approach described in this paper also draws from the fields of decision analysis, multi-attribute theory and negotiation theory to provide an alternative to the economic stated preference methods used to quantify the value of cultural ecosystem benefits (as represented by Potschin and Haines-Young in Fig. 1). Similar to the Service-to-Service approach used by HEA and REA, the value of cultural benefits using SDS can be estimated by scaling "Benefit-to-Benefit" between the injuries and the compensatory actions. Scaling under SDS can alternatively be done through a "Benefit-to-Cost" approach. Neither approach requires a direct placement of monetary value on impacted cultural benefits. The SDS methods described in this paper were first proposed by McDaniels and Trousdale [16] and expanded by Gregory and Trousdale [13] based on their work associated with the preservation and compensatory restoration of cultural service losses of indigenous people in Canada and the Pacific Northwest of the U.S. SDS is an organized approach to identify and evaluate creative alternatives and make transparent choices for complex decisions. It has been used for a wide variety of applications by both commercial and government organizations.

\section{KEY ELEMENTS IN SDS PROCESS FOR CULTURAL INJURIES}

The SDS Process is briefly summarized as a five-step process.

\subsection{Problem formulation and planning}

Evaluating the value of the cultural benefit losses (or gains) associated with environmental injuries from the incident of concern requires developing a broad understanding of the relevant environmental and anthropogenic interactions, influences, and concerns from a variety of perspectives. It can be useful to develop a conceptual model or influence diagram of the science, engineering, economic, cultural and legal considerations to depict this understanding and build trust and cooperation among impacted stakeholders. The problem formulation step involves defining how to identify and involve cultural experts and the impacted community, developing the assessment process, and defining how sensitive information will be collected and addressed [17], [18]. The outcomes of this step include an approach that is appropriate from the impacted parties' perspective but also rigorous, defensible, and transparent such that it can be understood by both the impacted and potentially responsible party.

\subsection{Defining cultural ecosystem service and their benefits for baseline and from the injuries}

This step is a facilitated, collaborative effort with the impacted community and/or technical experts representing that community where the objective is to identify cultural benefits important to relevant parties that have been, or may become, impacted. There are well established, iterative value elicitation processes that can be used to assess what changes 
occurred across multiple dimensions of cultural benefits relative to baseline, i.e., the condition of the natural resources all but for the incident being evaluated [19].

The SDS process is iterative, supported using analytical tools, it establishes the basis for identifying ways to measure benefits that are lost as a direct result of the release or discharge. The output of this benefit elicitation step is a means-end framework with cultural-means benefits $(\mathrm{CMB})$ and cultural-end benefits $(\mathrm{CEB})$ that can be measured with distinct, clear, concise, sensitive, understandable indicators providing insight and avoiding double counting (Fig. 4; for examples, see Keeney and Gregory [20] or Poe et al. [11]). Means-end frameworks help understand and communicate the relationship regarding what is important in contributing (i.e. $\mathrm{CMB}$ ) to a broader end-objective state (i.e. CEB).

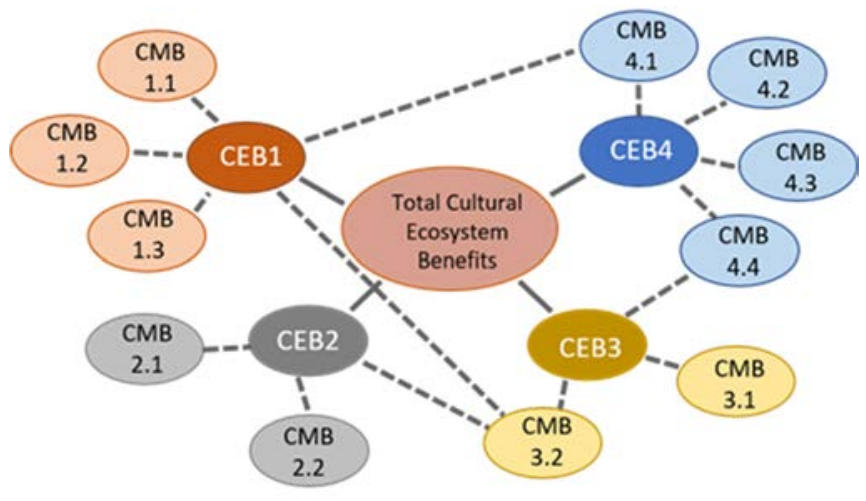

Figure 4: Establishing relationships between cultural end benefits (CEB) and cultural mean benefits (CMB).

\subsection{Quantifying severity of lost cultural services}

The CMBs and CEBs are derived from an understanding of the impacts to cultural ecosystem services and benefits. These changes are measured by comparing current and future states to baseline (the level of services that would have existed all but for the incident being evaluated). Although damage assessment experts frequently define baseline as a snapshot of the conditions that existed at the time of the perturbation of interest, consideration of how other natural and anthropogenic influences may affect baseline, excluding the incident or event being evaluated, should be considered. The impacted cultural benefits need to be measured to give them meaning for comparative evaluation purposes: quantifying cultural gains (if any) and losses with appropriate scaling of avoidance, mitigation, compensation, or compensatory restoration. As indicated, it is essential that these measures are understandable, especially by the cultural experts and broader affected parties who need to be included in the evaluation of impact and significance of the incident or event induced changes. Therefore, the measures are developed with their input. The level of impact can be expressed using natural measures (e.g., number of reported illnesses), proxies (e.g., number of acres of culturally significant land) or, for CEBs that are more difficult to measure, constructed scales can be used (e.g., a Likert scale that use quantitative and/or qualitative indicators to establish clear end points relative to baseline services and benefits and the most adverse change, either a priori or a posteriori (for examples, see Keeney and Gregory [20], Gregory et al. [21], Keeney and Sicherman [22] and Failing et al. [23]). For a priori evaluation of future scenarios 
where an incident may have both positive and negative impacts, baseline can be defined as the midpoint of the constructed scale rather than an endpoint. With a framework and measure in place, the loss of each cultural value from baseline can be evaluated over time (Fig. 5).

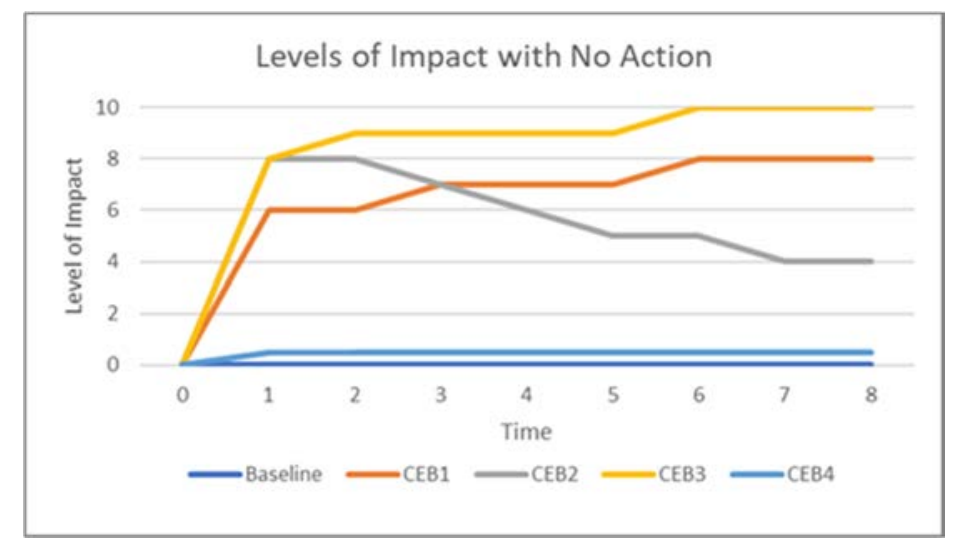

Figure 5: Quantifying severity of individual CEBs overtime (unweighted).

\subsection{Ranking relative importance of injured cultural services and benefits}

Cultural services and benefits and the corresponding impacts will likely have different levels of importance or significance to the individuals or groups who hold those values. A small impact to the most important cultural benefits may be more significant than moderate or large impacts to cultural benefits of lower importance. The goal in this step is to understand the relative importance of each independent CEB value, and how those differences may affect the overall estimate of service loss. The relative importance is captured through the process of identifying importance weights. It is advantageous to use multiple methods to help affected stakeholders consider the relative importance of change and provide quantifiable weights (e.g., scaled pairwise comparison, point allocation, swing weighting, etc.; Fig. 6) [24].

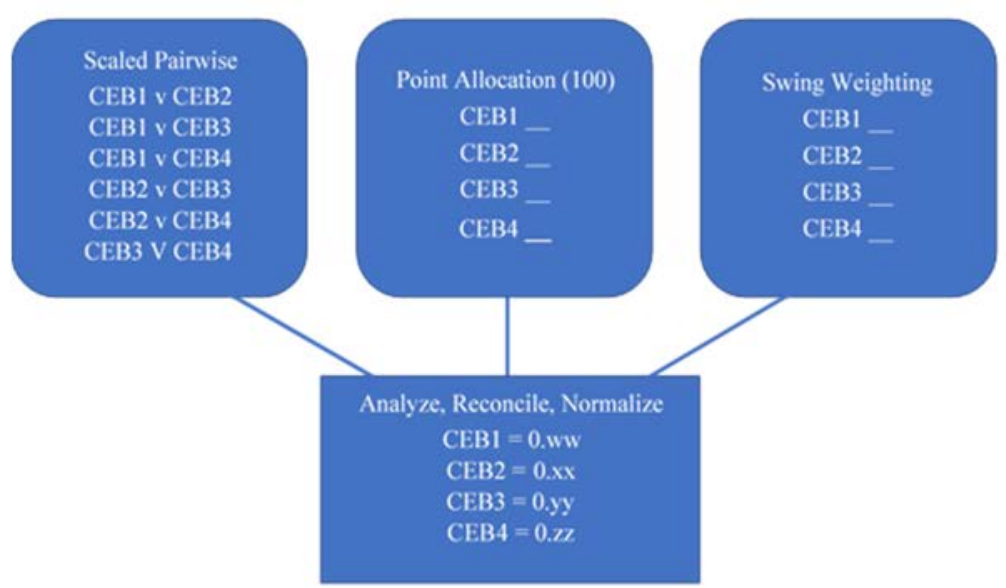

Figure 6: Example of multiple methods to weight relative importance of individual CEBs. 
Once the relative importance among individual participants of CEBs is established, cultural impacts among the various CEBs can be normalized based on their relative importance by multiplying each CEB's relative priority times the unweighted change over time for each $\mathrm{CEB}_{\mathrm{x}}$. Table 1 shows an abbreviated example of this calculation (i.e., due to space limitations, we include only 3 years of the change in $\mathrm{CEB}_{\mathrm{x}}$ from Fig. 5 and excluded CEB4 due to the minimal impact to this value). The unweighted data Table 1 would suggest the cumulative cultural impact (CEB1 + CEB2 + CEB3) under no action was relatively stable in the during the first eight years with impacts to CEB3 being slightly more important in determining the cumulative impact than the other two CEBs. In contrast, the normalized (weighted) relative value analysis clearly demonstrates how CEB1 drives the cumulative cultural impact, suggesting that avoidance, mitigation, restoration, or compensation activities that more effectively address this CEB should be the initial focus.

Table 1: Example of weighted $\mathrm{CEB}_{\mathrm{x}}$ response (abbreviated due to space limitations).

\begin{tabular}{|c|c|c|c|c|c|c|c|c|c|}
\hline \multirow[t]{2}{*}{$\begin{array}{l}\text { Cultural } \\
\text { benefit }\end{array}$} & \multirow{2}{*}{$\begin{array}{l}\text { Relative } \\
\text { CEBx } \\
\text { weight }\end{array}$} & \multicolumn{3}{|c|}{$\begin{array}{l}\text { Unweighted } \\
\text { CEBx } \\
\text { response by year }\end{array}$} & \multirow[t]{2}{*}{$\begin{array}{l}\text { Unweighted } \\
\text { subtotal }\end{array}$} & \multicolumn{3}{|c|}{$\begin{array}{l}\text { Value weighted } \\
\text { response by year }\end{array}$} & \multirow[t]{2}{*}{$\begin{array}{c}\text { Weighted } \\
\text { subtotal }\end{array}$} \\
\hline & & 1 & 4 & 8 & & 1 & 4 & 8 & \\
\hline CEB1 & 0.78 & -6 & -7 & -8 & -21 & -4.7 & -5.5 & -6.2 & -16.4 \\
\hline CEB2 & 0.09 & -8 & -6 & -4 & -18 & -0.7 & -0.5 & -0.4 & -1.6 \\
\hline CEB3 & 0.13 & -8 & -9 & -10 & -27 & -1.0 & -1.2 & -1.3 & -3.5 \\
\hline Total & 1.00 & -22 & -22 & -22 & -68 & -6.4 & -7.2 & -7.9 & -21.5 \\
\hline
\end{tabular}

2.5 Defining cultural service values: Scaling the cultural benefits of avoidance, mitigation, restoration, or compensation activities with the lost benefits

The next step is to explore how the potential or actual cultural benefit impacts associated with the incident of concern may be addressed with appropriate avoidance, mitigation, restoration, or compensation responses. The specific methods for accomplishing this step can be quite varied depending on whether the objective is to select among alternative approaches of a proposed project (i.e., how best to avoid, mitigate, or compensate potential future impacts) or to restore a past injury and compensate for lost benefits. Sections 2.5.1 and 2.5.2 below provides a summary of two example approaches: Section 2.5.1 an approach to scale the avoidance, mitigation, restoration, or compensation activities based on a "Benefit-to-Benefit" scaling process, whereas Section 2.5.2 defines a scaling approach based on a "Benefit-to-Cost" process. The "Benefit-to-Benefit" approach can be more rigorous and objective than the "Benefit-to-Cost" approach. For some applications, simply calculating the potential impacts to cultural benefits for each alternative may be adequate needing to scale potential cultural benefit losses with avoidance or compensatory activities as defined below.

\subsubsection{Benefit-to-Benefit scaling}

"Benefit-to-Benefit" scaling of cultural impacts is similar to "Service-to-Service" scaling of ecological habitat using HEA and REA in that potential or past service cultural service and/or benefit losses due to environmental injuries are scaled to provide an equivalent value from primary and/or compensatory restoration from potential mitigation activities or restoration projects. This requires the identification of a range of avoidance, mitigation, restoration, or other compensatory activities which have a nexus to the injury. Equivalency is based on 
identifying a portfolio of cost-effective alternative activities or projects which are evaluated as to their impact on each $\mathrm{CEB}_{\mathrm{x}}$ over time (Fig. 7) utilizing the same Likert or constructed scale that was used in evaluating potential or past benefit losses (Fig. 5) which are then normalized by each $\mathrm{CEB}_{\mathrm{x}}$ 's relative value (Fig. 6 and Table 2). The economic value of the settlement is based on the sum of the applicable implementation costs for the selected compensatory activities or projects rather than a direct economic valuation of the cultural benefits. This process involves facilitated and structured discussion between technical experts, cultural experts and affected community stakeholders, supported by best practices and field visits. There are many tools to support this kind of analysis, such as slider scales and consequence tables which are helpful visual tools, as many specific actions will likely contribute to addressing losses to more than one value. The approach has similarities to that of negotiation analysis, in which the scope for more attractive agreements is explored by focusing on different stakeholder "interests" (for examples, see Fisher and Ury [25] and Raiffa [26]). The primary difference is that this approach is structured around a co-generated framework and supported by tools, techniques and methods where quantitative expressions of how well alternatives address losses can be gauged.

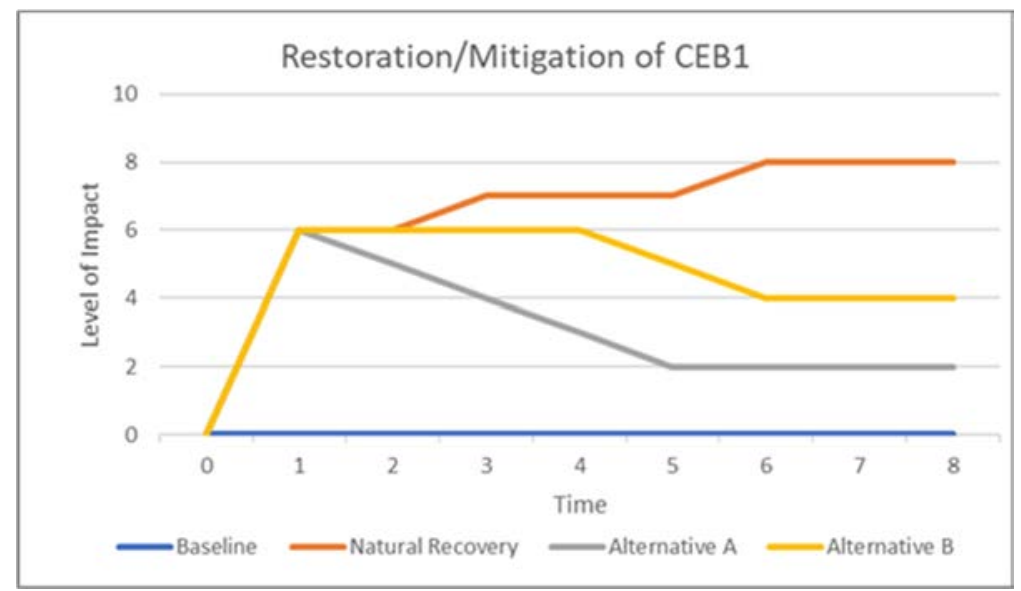

Figure 7: Unweighted restoration impacts on CEB1.

Table 2: Alternative restoration unweighted and weighted CEBs.

\begin{tabular}{|c|c|c|c|c|c|c|c|}
\hline \multirow{2}{*}{$\begin{array}{c}\text { Cultural } \\
\text { benefit }\end{array}$} & \multirow{2}{*}{$\begin{array}{c}\text { Normalized } \\
\text { weight }\end{array}$} & \multicolumn{3}{|c|}{$\begin{array}{c}\text { Unweighted response } \\
\text { in year } 8\end{array}$} & \multicolumn{3}{c|}{ Value weighted } \\
& & $\begin{array}{c}\text { No } \\
\text { action }\end{array}$ & $\begin{array}{c}\text { Alt. } \\
\text { A }\end{array}$ & $\begin{array}{c}\text { Alt. } \\
\text { B }\end{array}$ & $\begin{array}{c}\text { No } \\
\text { Action }\end{array}$ & $\begin{array}{c}\text { Alt. } \\
\text { A }\end{array}$ & $\begin{array}{c}\text { Alt. } \\
\text { B }\end{array}$ \\
\hline CEB1 & 0.78 & -8 & -2 & -4 & -6.2 & -1.6 & -3.1 \\
\hline CEB2 & 0.09 & -6 & -5 & -2 & -0.5 & -0.5 & -0.2 \\
\hline CEB3 & 0.13 & -10 & -9 & -6 & -1.3 & -1.2 & -0.8 \\
\hline Total & 1.00 & -24 & -16 & -12 & -8.1 & -3.1 & -4.1 \\
\hline
\end{tabular}

The restoration alternative with the largest reduction in the level of total unweighted CEB injuries (alternative B in Table 2) may not be the preferred alternative when lower ranked CEBs respond more than higher preferred CEBs. Note that Table 2 is for illustrative purposes 
due to space limitations and provides only partial primary restoration and no compensatory restoration. The process of scaling potential or past impacts with the benefits of various restoration activities is functionally similar to scaling habitat services using HEA or REA and extensively documented in the literature.

\subsubsection{Benefit-to-Cost scaling}

Benefit-to-Cost scaling of cultural losses with appropriate avoidance, mitigation, restoration, or compensation activities is useful in the following situations: (1) insufficient information is available to define potential avoidance or compensatory activities (i.e., Benefit-to-Benefit scaling; (2) there is value in establishing monetary equivalents for comparative purposes, to translate losses into a common "language of business", to capture residual losses not addresses by Benefit-to-Benefit; or (3) the value of a "Benefit-to-Benefit" scaling approach is not warranted among various stakeholders based on the added cost, time, and complexity for a more rigorous assessment.

Benefit-to-Cost scaling can be conducted when one or more of the CEBs can be related directly to a financial value using market or revealed cost economics. If this condition is met, then the CEB is relabelled as a Financial End Benefit (FEB). Knowing the level of impact of each CEB and the FEB as well as their relative importance allows each CEB to be priced out in financial terms and then summed to identify an estimated value of the total impacted cultural benefits. Benefit-to-Cost scaling can be explored as a complement to the Benefit-toBenefit approach provided the assumptions and inputs to the evaluation are appropriate and defensible. The complementary or integrated approach allows for the inclusion of a combination of compensatory activities and compensation, including the pricing out of residual damages, in order to create a cost-effective yet appropriate type and level of compensation. Finally, multiple cost approaches provide opportunity to test the sensitivity and robustness of the evaluation.

\section{DISCUSSION}

The SDS method outlined here provides a quantitative relative value of impacted cultural services and their benefits that facilitates the identification of cost-effective alternatives from the multiple perspective of involved parties. The processes include process facilitators working with technical experts (e.g., cultural, ecological) and the affected parties. The method can be used to support negotiations, mediations or decisions (such as legal actions). The use of SDS results in the avoidance or minimization of potential future impacts associated with proposed development projects as well as appropriate avoidance, mitigation, restoration, or compensation past injuries associated with adverse anthropogenic events (e.g., releases of hazardous substances, severe wildfires, mining development, etc.). SDS is compatible for use in conjunction with other methods to define ecological and direct use service losses (e.g., HEA for ecological habitat services and revealed preference addressing compensatory restoration for lost recreational) without double counting by including projects developed to compensate habitat and recreational use losses in the cultural evaluation.

Confidentiality of cultural resources, values, and sacred sites can be a concern with some affected parties in certain instances (e.g., indigenous groups). However, some circumstances can be addressed without sharing specific, detailed information (e.g., avoiding development in a culturally sensitive or sacred area), or mitigation and restoration alternatives can be generated without specific definition of confidential information. Experience working with First Nation communities in British Columbia confirm that the SDS approach can be implemented without revealing sensitive confidential information when a significant level 
of trust has been established and these issues addressed in the problem formulation and planning stage.

Scaling of injuries to cultural benefits with offsetting compensation activities or projects requires equating cultural benefit values over time. Extensive literature exists regarding how to define applicable discounting rates for natural resources, and government regulations and guidance can vary greatly. It is beyond the scope of this paper to discuss this topic thoroughly. It is noted; however, that the appropriateness for discounting someone else's cultural benefits and values over any period of time warrants thoughtful consideration.

The SDS approach to scaling total lost cultural benefits as represented here is helpful because it provides critical insight into each $\mathrm{CEB}$, which promotes more appropriate responses while at the same time providing a quantitative additive model allowing for aggregation of the independent $\mathrm{CEB}_{\mathrm{x}}$ values. This approach provides flexibility in finding acceptable and cost-effective avoidance, mitigation, restoration, or compensation alternatives. The SDS approach outlined here is helpful in many contexts where important but difficult cultural values are affected, where meaningful engagement is required or needed, and where there is a sincere desire to be more comprehensive, transparent and appropriate in addressing cultural impacts and losses.

\section{ACKNOWLEDGEMENTS}

We gratefully acknowledge the National Science Foundation (grant to Decision Research \#1728807) and U.S. Department of Interior for previous support on this topic in addition to comments from Dr. Robin Gregory. Responsibility for the ideas expressed in this paper rest with the authors alone.

\section{REFERENCES}

[1] Millennium Ecosystem Assessment, Ecosystems and Human Well-Being, Island Press: Washington, DC, 2005.

[2] Potschin, M.B. \& Haines-Young, R.H., Ecosystem services: Exploring a geographic perspective. Progress in Physical Geography, 35(5), pp. 575-594. 2011.

[3] Milcu, A., Hanspach, J., Abson, D. \& Fischer, J., Cultural ecosystem services: A literature review and prospects for future research. Ecology and Society, 18(3), 2013. www.jstor.org/stable/26269377. Accessed on: 1 May, 2020.

[4] Haines-Young, R. \& Potschin, M.B., Common International Classification of Ecosystem Services (CICES) V5.1 and guidance on the application of the revised structure 2018. www.cices.eu.

[5] Potschin-Young, M., R. Haines-Young, R., Gorg, C., Heink, U., Jax, K. \& Schleyer, C., Understanding the role of conceptual frameworks: Reading the ecosystem service cascade. Ecosystem Services, 29, pp. 428-440, 2018.

[6] La Notte, A. et al., Ecosystem Service classification: A systems ecology perspective of the cascade framework. Ecological Indicators, 74, pp. 392-402, 2017.

[7] Olander, L.P. et al., Benefit relevant indicators: Ecosystem services measure that link ecological and social outcomes. Ecological Indicators, 84, pp. 1262-1272, 2018.

[8] Bryce, R., Irvine, K.N., Church, A., Fish, R., Ranger, S. \& Kenter, J.O. Subjective well-being indicators for large-scale assessment of cultural ecosystem services. Ecosystem Services, 21(16), pp. 258-269, 2016.

[9] Hermann, A. et al., Assessment framework for landscape services in European cultural landscapes: An Austrian Hungarian case study. Ecological Indicators, 37, pp. 229240, 2014. 
[10] van Riper, C.J. \& Kyle, G.T., Capturing multiple values of ecosystem services shaped by the environmental worldviews: A spatial analysis. Journal of Environmental Management, 145(2014), pp. 374-386, 2014.

[11] Poe, M.R., Donatuto, J. \& Satterfield, T., "Sense of place": Human wellbeing considerations for ecological restoration in puget sound. Coastal Management, 44(5), pp. 1-18, 2016. DOI: 10.1080/08920753.2016.1208037.

[12] U.S. Environmental Protection Agency Science Advisory Board, Valuing the protection of ecological systems and services: A report of the EPA Science Advisory Board, EPA- SAB-09-012 May 2009, Washington, DC.

[13] Gregory, R. \& Trousdale, W., Compensating aboriginal cultural losses: An Alternative approach to assessing environmental damages. Journal of Environmental Management, 90(9), pp. 2469-2479, 2009.

[14] Knetsch, J., Environmental policy implications of disparities between willingness to pay and compensation demanded measure of value. Journal of Environmental Economics and Management, 18, 227-237, 1990.

[15] Fish, R., Church, A. \& Winter, M., Conceptualizing cultural ecosystem services: A novel framework for research and critical engagement. Ecosystem Services, 21, pp. 208-217, 2016.

[16] McDaniels, T.L. \& Trousdale, W., Evaluating losses of traditional native values with community-based multi-attribute value analysis. Ecological Economics, 55(2), pp. 173-186, 2005.

[17] Donatuto, J., Grossman, E., Konovsky, J., Grossman, S. \& Campbell, L., Indigenous community health and climate change: Integrating biophysical and social science indicators. Coastal Management, 42(4), pp. 355-373, 2014.

[18] Donatuto, J., Campbell, L. \& Gregory, R., Developing response indicators of community health. International Journal of Environmental Research and Public Health, 13, p. 899, 2016.

[19] Kenney, R.L., Value-Focused Thinking: A Path to Creative Decisionmaking, Harvard University Press: Cambridge, MA, 1992.

[20] Keeney, R.L. \& Gregory, R., Selecting attributes to measure the achievement of objectives. Operations Research, 53(1,) pp. 1-11, 2005.

[21] Gregory, R., Easterling, D., Kaechele, N. \& Trousdale, W., Values-based measures of impacts to indigenous health. Risk Analysis, 36(8), pp. 1581-1588, 2016.

[22] Keeney, R. \& Sicherman, A., Illustrative comparison of one utility's coal and nuclear choices. Operations Research, 31(1), pp. 50-83, 1983.

[23] Failing, L., Gregory, R. \& Higgins, P., Science, uncertainty, and values in ecological restoration: A case study in structured decision-making and adaptive management. Restoration Ecology, 21(4), pp. 422-430, 2013

[24] Hobbs, B.F. \& Horn, C.T., Building public confidence in energy planning: A multimethod MCDM approach to demand-side planning at BC gas. Energy Policy, 25(3), pp. 357-375, 1997.

[25] Fisher, R. \& Ury, W., Getting to Yes: Negotiating Agreement Without Giving in, Houghton Mifflin: Boston, MA, 1981.

[26] Raiffa, H., The Art and Science of Negotiation, Harvard University Press: Cambridge, MA, 1982. 